\title{
Direct in-vitro assay of resistant starch in phosphorylated cross-linked starch
}

\begin{abstract}
Direct assay of resistant starch (RS) in food and feed is accomplished by (i) removal of lipid, protein, and digestible starch to obtain insoluble dietary fiber, and (ii) dissolution of the resistant starch in the insoluble fiber followed by its quantification with specific enzymes. Phosphorylated cross-linked (CL) RS resists dissolution and therefore has not been assayed directly. The objective of this study was to develop a method to solubilize the RS fraction in phosphorylated $(0.4 \%$ phosphorus) CL wheat starch (RS4) after its incubation with $\alpha$ amylase and amyloglucosidase for $16 \mathrm{~h}$ at $37{ }^{\circ} \mathrm{C}$ as directed by the RS assay AOAC Method 2002.02. The residue was hydrolyzed and solubilized by conducting two back-to-back incubations with thermostable $\alpha$-amylase for $30 \mathrm{~min}$ at $100{ }^{\circ} \mathrm{C}$ and $\mathrm{pH} \mathrm{5.0,} \mathrm{cooling} \mathrm{to} 50{ }^{\circ} \mathrm{C}$, then incubating quickly with amyloglucosidase at $50{ }^{\circ} \mathrm{C}$ for $1 \mathrm{~h}$ at $\mathrm{pH} 5.0$. Importantly, the cooling process after $\alpha$-amylase incubation was done by placing the mixture in a water bath at $50{ }^{\circ} \mathrm{C}$. The degree of hydrolysis of the CL phosphorylated wheat starch was determined as dglucose using high-performance anion-exchange chromatography with pulsed amperometric detection (99.0\%), glucose-oxidase/peroxidase (95.3\%), and phenol-sulfuric acid determination of total carbohydrate $(105.2 \%)$. Based on those findings, we propose a direct determination of RS in foods containing phosphorylated CL wheat starch.
\end{abstract}

Keyword: Type 4 resistant starch; In-vitro test; Solubility 